\title{
Prolonged Middle Ear Ventilation by Cartilage-Grommet Tympanoplasty
}

\author{
Kartik Parelkar, Smita Nagle, Mohan Jagade, Vandana Thorawade, Poonam Khairnar, \\ Anoop Attakil, Madhavi Pandare, Rajanala Nataraj, Reshma Hanwate, Rajesh Kar \\ Department of ENT, Grant Government Medical College \& Sir J J Group of Hospitals, Mumbai, India \\ Email: kartikparelkar@ymail.com
}

Received 12 November 2014; revised 28 November 2014; accepted 9 December 2014

Copyright (C) 2015 by authors and Scientific Research Publishing Inc.

This work is licensed under the Creative Commons Attribution International License (CC BY).

http://creativecommons.org/licenses/by/4.0/

(c) (i) Open Access

\begin{abstract}
In 1994, the American Otological Society reported favourable experience with composite cartilage shield tympanoplasty. The tragal cartilage with a grommet inserted in it was used for tympanoplasty in our patient with unilateral CSOM, supposedly because of severe chronic eustachian tube dysfunction. The marriage of cartilage tympanoplasty with grommet insertion was aimed to add the advantages and abolish the disadvantages of both the procedures. In 1990 Lary Hall first introduced the "long term ventilation of the middle ear" with a T-tube placed in the tragal cartilage perichondrium composite island graft. T-tube insertion in the cartilage has been described. But insertion of the Indian Sheperds grommet (ventilation tube) in the cartilage graft as described in this case and its technique are possibly the first of its kinds in literature. The report is aimed to ignite innovation of newer and better techniques of cartilage tympanoplasty.
\end{abstract}

\section{Keywords}

Tragal Cartilage, Grommet, Tympanoplasty

\section{Introduction}

The aim of tympanoplasty is to reconstruct the tympanic membrane and the sound conducting mechanism.

In 1990 Lary Hall first introduced the technique of cartilage T-tube tympanoplasty, the goal of placement of the permanent tube is to prevent repeated insertions of ventilating tubes, especially in children with severe and chronic secretory otitis media.

Chronic severe eustachian tube dysfunction is the main indication of cartilage shield T-tube tympanoplasty; such a situation most often is present in craniofacial abnormalities, downs syndrome, nasopharyngeal adenoid cystic carcinoma, previous head neck cancers involving the nasopharynx. 
Also this technique can be used in cases with recurrences of chronic otitis media and history of multiple surgeries with chronic eustachian tube dysfunction as the possible eitiolgy. Recurrent long term middle ear effusion and atelectasis also can be managed by this method.

Prolonged middle ear ventilation is possible when a ventilation tube is inserted in the cartilage graft.

The possibility of grommet migration and displacement due to proliferation of the epithelial layer of tympanic membrane are reduced in this technique.

We would thus like to report our experience of cartilage-grommet tympanoplasty in this case.

\section{Case Report}

A 17-year-old male (Figure 1) with right ear discharge since 7 years presented to our out-patient department. The discharge was mucopurulent, non-foul smelling, intermittent and non-blood tinged. Patient had no active mucopurulent ear discharge since last 6 months.

On otoscopy right tympanic membrane showed large central perforation with a small tympanosclerotic patch in the anterosuperior quadrant while the left tympanic membrane was intact showing grade 4 retraction.

Patient had valsalva test and methylene blue dye test negative on both sides.

On tuning fork tests, Webers was lateralized to the right ear. Rinnes test was negative for the right ear.

Pure tone audiogram showed right ear mild to moderate conductive hearing loss.

Patient had right sided $2 \times 2 \mathrm{~cm}$ sized lymph node over the right mastoid tip, no scalp infection.

FNAC (fine needle aspiration cytology) of which was suggestive of inflammatory cells.

Patient was taken up for right ear cartilage-grommet tympanoplasty after meticulous routine pre-anaesthetic investigations.

Tragal cartilage graft was harvested (Figure 2) with perichondrium on both sides. The margins of the perforation were freshened and tympanosclerotic patch was removed. Appropriate size and shape of the graft was fashioned. The antero-inferior quadrant of the graft was noted and marking for the site of grommet insertion made with methylene blue dye on a needle.

The perichondrium from over the lateral surface of the graft was raised all along its margins and a part of it over the grommet insertion site excised.

A small hole was made at the marked site with a cutting burr matching the approximate diameter of the grommet through which the grommet ( $0.75 \mathrm{~mm}$ internal diameter made of teflon) was inserted (Figure 3 ).

There was evidence of glue like secretion in the hypotympanum and retrotympanum which was suctioned out.

Post auricular Wildes incision was made, the lymphnode was dissected out and sent for HPR (s/o inflammatory cells, no evidence of tuberculous pathology).

Tympanomeatal flap was elevated and the cartilage-grommet graft placed in an underlay fashion (Figure 4), while the perichondrium over the lateral aspect was spread in an overlay manner except in the region of the grommet.

Gelfoam was kept in the EAC and the postauricular wound closed in layers. Post operative period was uneventful.

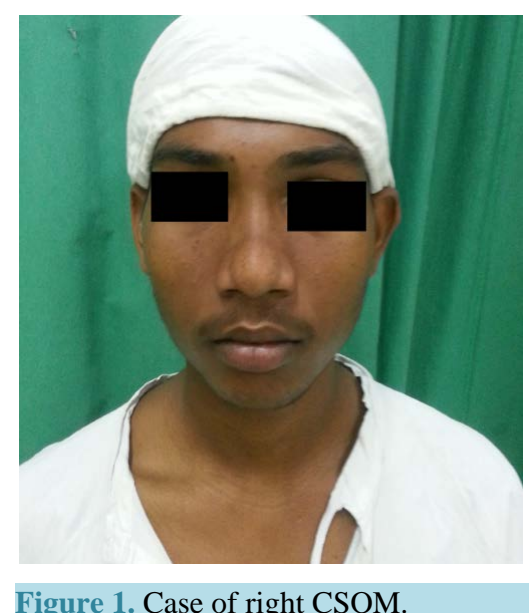




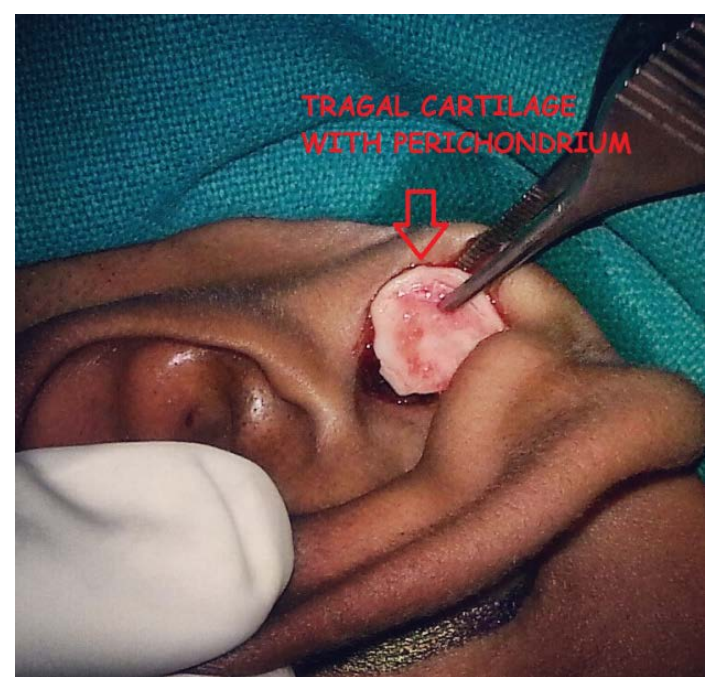

Figure 2. Tragal cartılage being harvested.

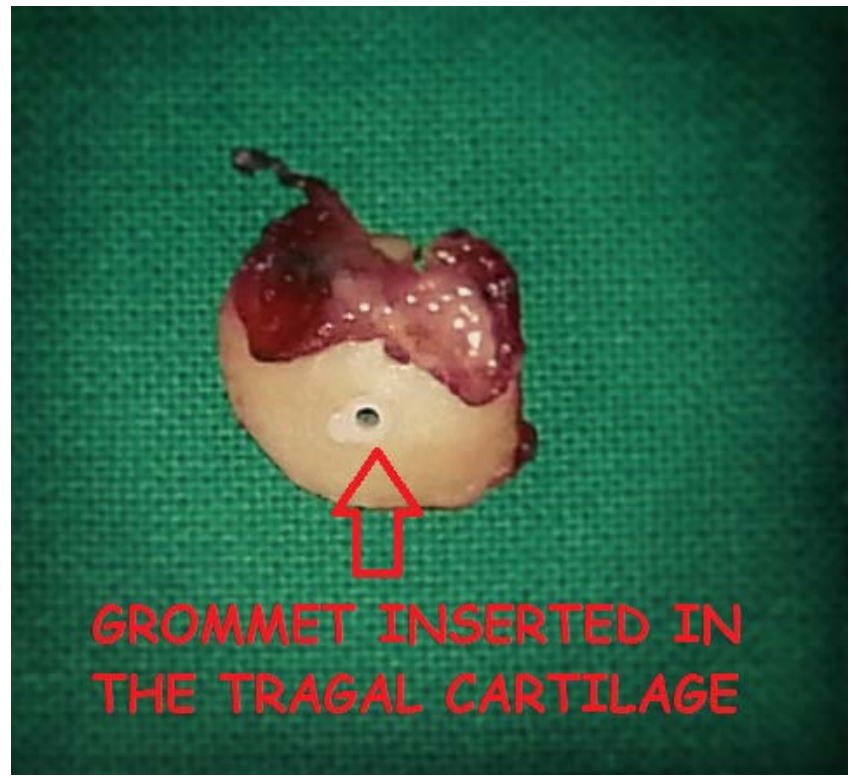

Figure 3. Composite tragal cartilage graft with inserted grommet.

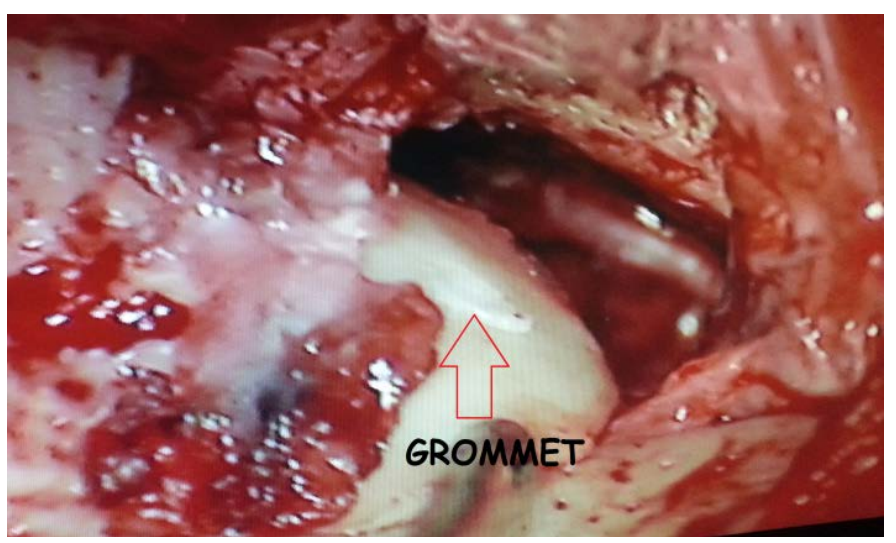

Figure 4. Cartilage-grommet graft being placed in underlay fashion. 


\section{Discussion}

Since the introduction of tympanoplasty, in the fifties, by Zoellner [1] and Wullstein [2], numerous graft materials have been used for the closure of the defective membrane: skin, fascia lata, temporalis fascia, vein, perichondrium, dura mater [3]-[5].

Even today, temporalis fascia remains the most commonly used material for tympanic membrane reconstruction with a success rate of $93 \%-97 \%$ in primary tympanoplasties [6].

In certain situations, such as recurrent perforation following myringoplasty, severe attical or posterior uncontrolled retraction pockets with cholesteatomatous formation, atelectasis of the tympanic membrane, fascia and perichondrium may undergo atrophy and subsequent failure, irrespective of the placement technique used [7].

In these patients, cartilage can be used as a grafting material on account of its increased stability and resistance to negative middle ear pressure, even in cases with chronic eustachian tube dysfunction [8].

It has been proved, both in experimental and clinical studies, that cartilage is well tolerated by the middle ear and shows long term survival [9] [10].

However, acceptance of routine reconstruction of the tympanic membrane with cartilage has been hampered by its reputation of sacrificing maximum hearing improvement, although various studies have shown that the hearing results are good, regardless of the thickness of the grafts [11]-[14].

Though in our case postauricular approach was used with a view to remove the lymph node over the mastoid tip, transcanal technique to harvest and place the composite tragal cartilage graft can be done. The transcanal technique is minimally invasive and sutureless one, with reduced hospital stay and better patient compliance.

Duckert, Muller, Malkielshi and Helms (1995) from university of Washington and university of Wirzburg have developed an interesting cartilage T-tube device to ventilate the tympanic cavity for prolonged period of time.

There are different methods of cartilage T-tube tympanoplasty i.e. Hall cartilage shield T-tube graft, Duckert cartilage graft, Dornhoffer graft and Elsheikh U-shaped cartilage perichondriun T-tube graft [15] [16].

In our technique a graft similar to the Duckert cartilage shield with a V-shaped notch to accommodate the handle of malleus was made.

Inserting the grommet in the cartilage graft is technically difficult, a pick can be used to gradually dilate a small hole made in the cartilage but in our experience an appropriate ossiculoplasty cutting burr is a better option to make the required hole for grommet insertion.

The cartilage shield T-tube tympanoplasty can effectively reverse atelectasis and provide prolonged middle-ear ventilation. The technique can be used safely and minimizes the risk of tympanic membrane perforation and other complications associated with prolonged middle ear intubation [16]. Patients undergoing tympanoplasty with this technique require long term follow-up though Dukert et al. (2003) have not found any extrusion of the tubes among 40 patients of their latest series.

The safety and efficacy of tympanoplasty in conjunction with anteriorly placed subannular T-tubes was examined by Elluru et al. [17].

Elsheikh et al compared the results for cartilage tympanoplasty with and without T-tube placement in those patients with atelectactic tympanic membrane though safe they found no particular advantage in primary insertion of ventilation tube in their study [18].

Reinsertion of the T-tube in case of extrusion can be done through the same hole in the cartilage and is relatively easy as risk of medializing the graft is reduced due to the increased rigidity of the graft.

However in our case as the grommet doesn't have flanges which can open up like the T-tube, hence resinsertion would be very difficult.

Closure of the ventilating tube by overlying cerumen can be managed by regular follow-up for cleaning and suctioning with a fine suction cannula.

There maybe chances of granulation tissue formation near the grommet site which can be managed by instillation of steroid containing drops.

Granulation tissue forms in 10\% - 20\% of cases (Danner and Dornhoffer, 2001), but it responds well to steroid containing drops and has never prompted tube removal.

Also coloured grommet would be a better option to use as it would be easier to visualize the grommet inserted in the cartilage both during the procedure and postoperatively.

Though only valsalva and methylene blue dye test along with the clinical and intra-operative findings (glue in middle ear) were used to suggest eustachian tube dysfunction as the possible eitiological factor for the chronic suppurative otitis media, it would be advisable to measure tubal patency and function by series of other tests as 
well.

Tympanometery and measurement of tubal function with deflation test and aspiration test should be done.

Our patient is on regular follow-up since 1 month postoperatively with no evidence of displacement of the grommet.

Pure tone audiogram will be repeated after 6 months and follow-up will be continued.

\section{Conclusions}

Tragal cartilage-grommet tympanoplasty requires specifications for patient selection. A defined set of tests pointing at eustachian tube dysfunction as a causative factor of the chronic suppurative otitis media are also required.

Through an attractive technique long term follow-up of patient and randomised control trials for this technique will help to establish its efficiency in cases requiring prolonged middle ear ventilation.

\section{References}

[1] Zoellner, F. (1955) The Principles of Plastic Surgery of the Sound-Conducting Apparatus. The Journal of Laryngology Otology, 69, 567-569.

[2] Wullstein, H.L. (1952) Functional Operations in the Middle Ear with Split-Thickness Skin Graft. Arch Otorhinolaryngol, 161, 422-435. http://dx.doi.org/10.1007/BF02129204

[3] Heermann, H. (1960) Tympanic Membrane Plastic with Temporal Fascia. Archiv für Ohren-, Nasen- und Kehlkopfheilkunde, 9, 136-139.

[4] Shea, J.J. (1960) Vein Graft Closure of Eardrum Perforations. The Journal of Laryngology Otology, 74, 358-362. http://dx.doi.org/10.1017/S002221510005670X

[5] Preobrazhenski, T.B. and Rugov, A.A. (1965) The Employment of Preserved Dura Mater Graft in Tympanoplasty. Vestnik Otorinolaringologii, 5, 38-42.

[6] Sheehy, J.L. and Anderson, R.G. (1980) Myringoplasty. A Review of 472 Cases. Annals of Otology, Rhinology Laryngology, 89, 331-334. http://dx.doi.org/10.1177/000348948008900407

[7] Buckingham, R.A. (1992) Fascia and Perichondrium Atrophy in Tympanoplasty and Recurrent Middle Ear Atelectasis. Annals of Otology, Rhinology Laryngology, 101, 755-758. http://dx.doi.org/10.1177/000348949210100907

[8] Duckert, L.G., Muller, J., Makielski, K.H. and Helms, J. (1995) Composite Autograft “Shield” Reconstruction of Remnant Tympanic Membranes. American Journal of Otolaryngology, 16, 21-26.

[9] Yamamoto, E., Iwanaga, M. and Fukumoto, M. (1988) Histologic Study of Homograft Cartilage Implanted in the Middle Ear. Otolaryngology—Head and Neck Surgery, 98, 546-551.

[10] Hamed, M., Samir, M. and El Bigermy, M. (1999) Fate of Cartilage Material Used in Middle Ear Surgery Light and Electron Microscopy Study. Auris Nasus Larynx, 26, 257-262. http://dx.doi.org/10.1016/S0385-8146(99)00012-7

[11] Amedee, R.G., Mann, W.J. and Riechelmann, H. (1989) Cartilage Palisade Tympanoplasty. American Journal of Otology, 10, 447-450.

[12] Dornhoffer, J.L. (1997) Hearing Results with Cartilage Tympanoplasty. The Laryngoscope, 107, 1094-1099. http://dx.doi.org/10.1097/00005537-199708000-00016

[13] Gerber, M.J., Mason, J.C. and Lambert, P.R. (2000) Hearing Results after Primary Cartilage Tympanoplasty. The Laryngoscope, 110, 1994-1999. http://dx.doi.org/10.1097/00005537-200012000-00002

[14] Heermann, J. (1992) Autograft Tragal and Conchal Palisade Cartilage and Perichondrium in Tympanomastoid Reconstruction. Ear, Nose \& Throat Journal, 71, 344-349.

[15] Hall, L.J. (1990) T-Tube with Tragus Cartilage Flange in Long Term Middle Ear Ventilation. American Journal of Otology, 11, 454-457.

[16] Duckert, L.G., Makielski, K.H. and Helms, J. (2003) Prolonged Middle Ear Ventilation with the Cartilage Shield TTube Tympanoplasty. Otology \& Neurotology, 24, 153-157. http://dx.doi.org/10.1097/00129492-200303000-00006

[17] Elluru, R.G., Dhanda, R., Neely, J.G. and Goebel, J.A. (2001) Anterior Subannular T-Tube for Prolonged Middle Ear Ventilation during Tympanoplasty: Evaluation of Efficacy and Complications. Otology \& Neurotology, 22, 761-765. http://dx.doi.org/10.1097/00129492-200111000-00008

[18] Elsheikh, M.N., Elsherief, H.S. and Elsherief, S.G. (2006) Cartilage Tympanoplasty for Management of Tympanic Membrane Atelectasis: Is Ventilatory Tube Necessary? Otology \& Neurotology, 27, 859-864. http://dx.doi.org/10.1097/01.mao.0000226288.96423.ed 
Scientific Research Publishing (SCIRP) is one of the largest Open Access journal publishers. It is currently publishing more than 200 open access, online, peer-reviewed journals covering a wide range of academic disciplines. SCIRP serves the worldwide academic communities and contributes to the progress and application of science with its publication.

Other selected journals from SCIRP are listed as below. Submit your manuscript to us via either submit@scirp.org or Online Submission Portal.
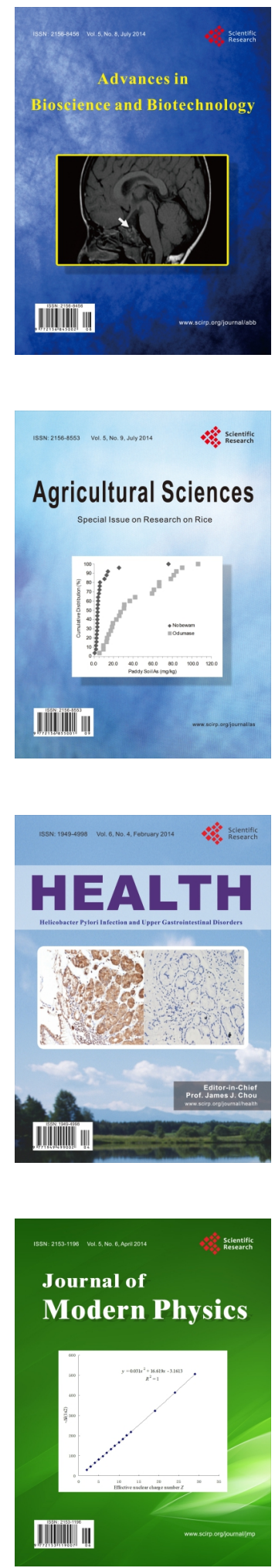
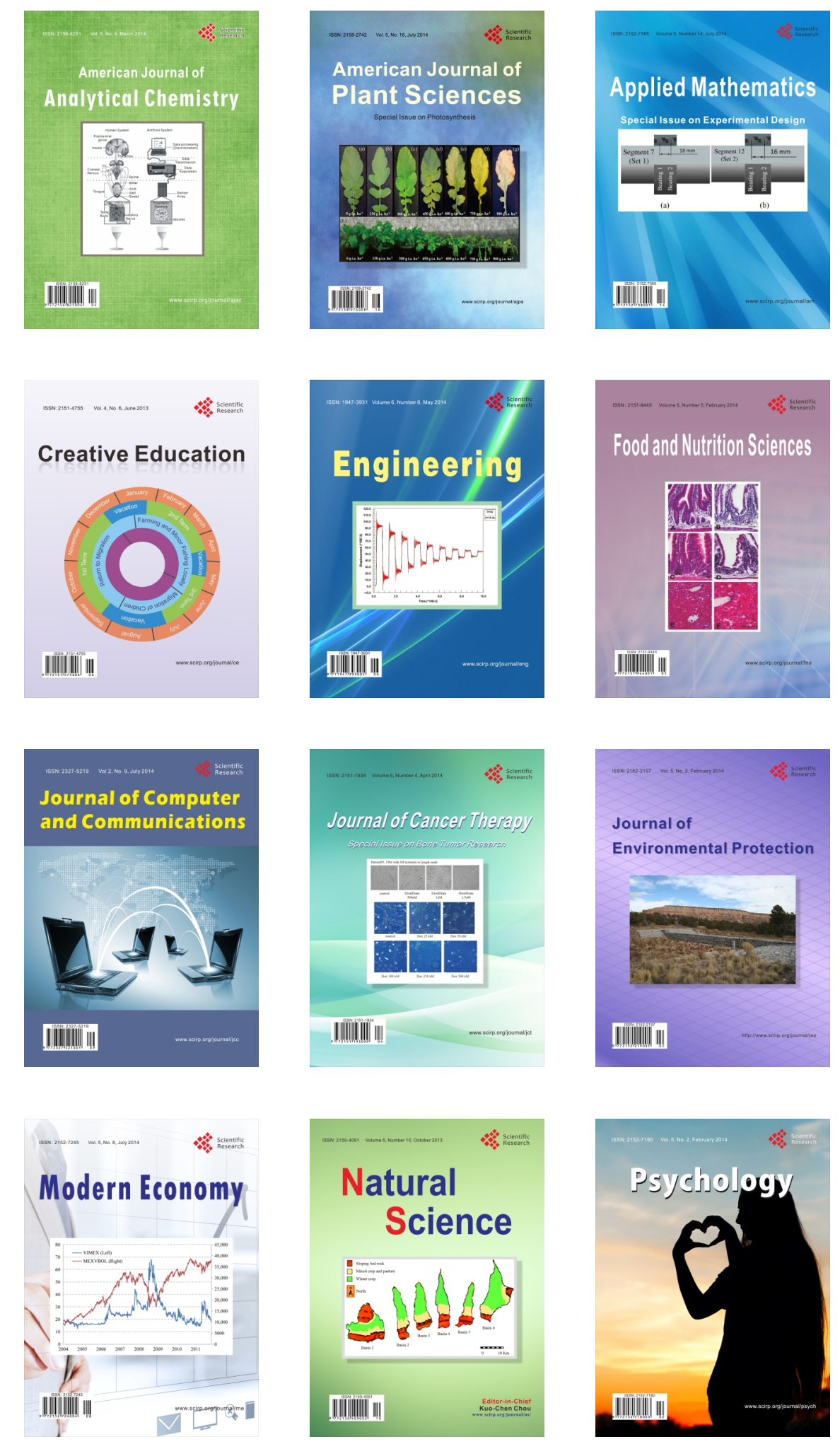